\begin{abstract}
What Not to Wear? Girls, clothing and 'showing' the body

Consumption practices of children in contemporary Western societies are implicated in the reconstruction of childhood, according to both popular debate and to those academic perspectives stressing the individualisation of identities within the life course of late modern consumer societies. Yet, little is known about the meanings children themselves give to their own consumption. Drawing from an ethnographic study of children aged 6 to 11 years and their families, the paper presents girls' constructions of fashion in relation to their own bodies and to those of others. It is shown that although girls may both desire and actually 'dress up' in contested clothing, they present a range of contingent and contradictory meanings for doing so. For some girls, 'dressing up' in certain clothes may be a way of 'ageing up' toward feminine adulthood, albeit in restricted contexts and after negotiations between themselves and their parents as to what can be worn and where. Nonetheless, girls in the study also showed anxieties and disapproval of 'showing the body' through 'revealing' clothing. The article concludes by considering the implication of these findings for debates about gendered childhoods, and intergenerational relations in late modern consumer society.
\end{abstract}




\section{What Not to Wear? Girls, clothing and 'showing' the body}

\section{Jane Pilcher}

Department of Sociology, University of Leicester, University Road, Leicester, LE1 7RH, England. Email: jlp3@le.ac.uk, Telephone: 01162522731

Word count: 8830 , excluding bibliography.

\section{Biography}

Jane Pilcher is Senior Lecturer in Sociology at the University of Leicester. Her main publications include Age and Generation in Modern Britain (Oxford University Press, 1995), Women in Contemporary Britain (Routledge, 2000) and Fifty Key Concepts in Gender Studies (with Imelda Whelehan, Sage, 2004). Her current research focuses on historical constructions of childhood within school health and sex education, and children's consumption of clothing fashions.

\section{Acknowledgements}

The research on which this article draws is funded under the ESRC/AHRB Cultures of Consumption programme (award number RES 143-25-0041), conducted by the author, with Christopher Pole, Tim Edwards and Sharon Boden. I particularly acknowledge the contribution made to the research reported in this paper by Christopher Pole and Sharon Boden, and, of course, to the children and their families. This paper was written during a period of study leave granted by the University of Leicester. 


\section{What Not to Wear? Girls, Clothing and 'Showing' the Body}

Existing literature largely fails to illuminate children's experiences and practices in relation to consumption (Martens, Southerton and Scott 2004), and especially in relation to clothing (although see Cook 2004; Cahill 1989; Russell and Tyler 2002; Swain 2002). There are emerging trends in late modern societies which now encourage academics to pay greater attention to the socio-cultural significance of children's clothing consumption. The market in children's clothing is considerable and growing (including in terms of designer labels), despite the falling birth rate (Aldridge 2004; Cook and Kaiser 2004; Euromonitor PLC 2004; Mintel 2003). It is in this context of expansion in the children's fashion market that the term 'tweenager' developed (Cook and Kaiser 2004; see also Johansson 2004). The term describes children aged between about eight and 12, especially girls, who are of interest to businesses because of their significant spending power on the High Street. The targeting of children by business and marketing along with children's own consumption of clothing as fashion, particularly if this is seen to 'sexualise' girls bodies, has been interpreted popularly as 'damaging' to childhood as a social institution. Although coming from quite different perspectives, there are some similarities between publicly voiced concerns about the sexualisation of feminine childhood through fashion and what can be described as academic 'postmodern consumption' perspectives, in that both allude to fashion's role in the weakening of the previously established generational boundaries between adulthood and childhood (Ash and Wilson 1993; Maffesoli 1996). However, Sweetman (2001: 73) is among several authors who criticise the idea of fashion cultures as a free floating 'carnival of signs', easily adopted and readily discarded, and who insist that fashion is at least partly structured by such statuses as age, stage in life course, and gender (Craik 1994; Edwards 2000; Kaiser 2001; Russell and Tyler 2002). 
Importantly, though trends in clothing fashions can only provide the broad context within which consumers (including children) exercise agency. The meanings of girls' encounters with controversial clothing fashion should not be 'read off' from market trends, or from media debates or the concerns of parents. Instead, they need exploring through an engagement with girls' everyday practices of clothing consumption.

\section{Methodology}

It is these concerns that have influenced the approach taken in the wider study of children, consumption and fashion, of which this paper is a part. Following focus group interviews with parents, fieldwork was undertaken in England in 2003-4 with eight families. Each family contained at least one child between the ages of six to 11 , whose consumption of children's clothing was tracked over a calendar year. The families were selected in accordance with well-established sociological methodologies (for example, Hammersley and Atkinson 1995), not to be representative of families in England in any statistical sense, but to be illustrative of key social variables, including income level, gender and ethnicity, urban and rural location. Data collection methods sought to place children at the centre of the research (Pole et al 1999) via deploying a range of participatory methods. Along with semi-structured interviews with and diary-work by parents, the methods collectively aimed to provide insight into the role of children as consumers of clothing within the context of different kinds of families across a full year. The study aimed to address gaps in existing knowledge about children's consumption of clothing, including for example, children's understandings and interpretations in respect of their own bodies, its mediation through generational relations in the household, and through peer relations, and the role it plays in contributing to children's experiences of social inclusion and exclusion. In order to provide an insight into the interconnected nature of children's consumption of clothing with its 
production, interviews were held with personnel in the children's wear industry, including store buyers and other executive decision makers.

Data presented in this paper are drawn from seven girls aged between 5 and 12, each of whom participated in five fieldwork visits and related project work over the course of a year. All of the seven girls featured in this paper were white ${ }^{1}$, and attended state schools. Data drawn from fieldwork visits with one girl, Hayley ${ }^{2}$ (aged 8), feature especially prominently in the paper. Of all the 28 children in the wider study, Hayley, was by far the most articulate in her interviews, writing and photographic project-work about her experiences and understandings of her consumption of clothing. As with other qualitative studies based on small samples, my intention is not to generalise from the experiences of Hayley or the other girls in our study to those of all girls, nor to develop from their experiences allencompassing theories of gendered childhoods, clothing and consumption. Rather, my aim in this paper is to examine the meanings of 'controversial' clothing fashions for the girls in our study and to suggest ways in which their understandings and experiences can inform, albeit in modest and provisional ways, both popular and sociological debates about the 'erosion' of gendered, generational boundaries in late modern societies. Accordingly, in the following section, I use data from the wider study to explore the meanings the girls themselves gave to controversial clothing fashions, both in relation to their own bodies and to those of others. In drawing upon key themes arising from the literature in the consumption of clothing and on the sociology of childhood reviewed earlier, the following questions are addressed. For the girls in our study, is 'dressing up' in controversial clothing about the 'innocent' pleasures of play, the 'otherness' of children's 'tribal culture' (James, Jenks and Prout 1998)? Or does it represent a more, reflexive 'knowing' engagement with fashion (McRobbie and Nava 1984) in order to 'age up' (Hockey and James 1993) toward a particular, overtly sexual model, of feminine adulthood (Cook and Kaiser 2004)? How is the 
girls' consumption of contested clothing shaped by the influence of peers (Elliot and Leonard 2004) and by negotiations with their parents (Prout 2000)? What are the girls' understandings of the symbolic character of clothing (Entwhistle and Wilson 2001; Cahill 1989), including in terms of the contextual 'presentation of self' and body (Goffman 1969; James, Jenks and Prout 1998; Prout 2000)?

\section{'Dressing Up': what to wear, and where}

Amongst the girls in the sample, aged between five and twelve, there is evidence of an active desire for and wearing of a range of clothing styles, shoes and accessories generally associated, at least in Britain, with 'emphasised' adult femininity (Connell 1995). These included high-heeled shoes and jewelry, and the more contentious items of fashion apparel such as crop-tops, halter-neck tops, and mini-skirts, central to sexualized presentations of adult femininity (Cook and Kaiser 2004). From our discussion with the girls, including based around their project work, there emerged a distinction between 'dressing up' in such clothing and accessories as a form of role play or rehearsal of adult femininity that was enacted inside the house, and 'dressing up' for 'going out'.

To introduce this theme in the data, I begin with the example of shoes with 'high heels'. These are recognizably long-established items of girls' ‘dressing up' paraphernalia, borrowed from their mothers' wardrobe, and through the boost in height they give the wearer, represent a practical (if temporary) means of 'growing up'. In our sample, the desire for high heels was evident even amongst the youngest girls. For example, Emma (aged five) drew pictures of herself wearing high heels; she said 'I'd like high ones [shoes] not low ones'. Katy (aged seven) both drew and cut-out pictures (from shopping catalogues) of high heels as items she would like to have: 'I quite like them and everyone at school has them'. Two slightly older girls, Megan and Hayley (both aged eight) each reported that they 
actually had their own high-heeled foot wear, and indeed showed them to us during our fieldwork visits. However, their consumption experiences were quite different in several respects. In Megan's case, several items of high heeled footwear were purchased for her by her mother, and were subsequently worn for a variety of 'going out' occasions with the full and active encouragement of her mother. Megan had a pair of high heeled boots with flower motif and beads. These, worn out to a special family occasion, were a favourite: 'I like high heels and I like the zip and I like the flower on it'. The boots were purchased by Megan's mother, after several attempts in different shops because of the difficulty in getting the right size. During a fieldwork visit, Megan presented a pair of sandals, styled with straps and with a one-and-a-half inch heel, and decorated with purple sequins, as another favourite pair of shoes. Megan said she wore these 'for all sorts' but especially for going out to 'discos and parties'. Her mother explained that after wearing these sandals, Megan often came home with sore feet; so much so that she could not wear them again for a few weeks. Megan was proud of her ability to walk in high shoes, and of her perseverance in doing so despite the discomfort they caused her, saying that her mother had said that she herself could not walk in them that high. This suggests that Megan gained a sense of 'ageing up' (Hockey and James 1993) through wearing the sandals: she displayed competency in wearing shoes that her own mother said she would have difficulty walking in. Moreover, Megan's consumption of high heeled footwear was important to her, not as a child's game of playing inside the house at dressing up, but instead in a more adult-like way, of dressing up to go out to events and occasions. Similarly, in her photo project, Megan had a photo taken of herself wearing camouflage-style trousers and a cropped, gypsy-style top ${ }^{3}$ which displayed her belly. She described them as her 'dressing-up clothes, my night out, going out night clothes, very, very trendy'. Clearly, for Megan, the fashionable 'trendiness' of the clothes was important, in keeping with a 'tweenager' style valuing of fashion amongst girls under twelve years old (Cook and Kaiser 2004; Mintel 2003). 
The case of Hayley and her high-heeled footwear further suggests the ways in which the meanings the girls gave to their clothing and footwear was mediated by interactions and negotiations with their parents, and especially their mothers. Hayley's favourite shoes were white platform-heel boots (of 1970s-style) and another high-heeled pair (measuring some five-and-a-half inches according to Hayley), both of which Hayley herself had purchased from a second-hand shop. As with Megan, competency in being able to walk in them, despite their height, was important; indeed the reason why they were in the second- hand shop was, according to Hayley, that the original owner(s) 'thought they were too high'. For Hayley, these shoes were 'cool' and also made her distinctive from her friends who did not have similar shoes: 'I'm one of the kind'. Despite Hayley's liking of such shoes, the 'ageing up' she gained from her skill in wearing them and the way they marked her unique style, she nonetheless regarded them as items for 'dressing up', inside the house. In her project work, Hayley chose a picture of shoes which she liked because they were 'quite high', but made it clear that she would not wear such shoes for going out, only for 'dressing up' inside the house. This use of high-heeled footwear in an inside-the-house rehearsal of adult femininity was very clearly an outcome of negotiations between Hayley and her mother, whose position on the wearing of high heels contrasted markedly with that of Megan's mother. In particular, Hayley was not allowed to wear her high-heeled shoes outside the house because 'they are too high and I think she might fall over' (Janet, Hayley's mother). Hayley was allowed to wear a favourite pair of high-heeled shoes to a special occasion of a birthday party, but notably, this was inside someone else's house.

Parental strategies that enabled or constrained the girls' desires for and consumption of adult-style attire were also evident in the case of clothing fashions that were contested, not because of the physical danger of falling over (as with the shoes), but because of moral 
danger arising from the ways in which they revealed the bare skin of the girls' bodies. Katy (aged seven) said that her mother did not really like her to have clothes with glitter or sparkle on them and that they often argued about the purchase and wearing of tops without any sleeves. As the following data extract makes clear, whilst for Katy, her mother especially disliked the embellishments (the glitter and sparkle) of the contested tops, Katy's mother herself pointed to the 'tarty' and 'revealing' styling of the clothing: : 'The only time I give in a little bit is the school disco'.

Similarly, in the following data extract, Hayley and her mother Janet are discussing a particular top which had caused a disagreement between them because it was too 'revealing':

Hayley: I don't even wear it.

Janet: No, well that was 'cos I didn't really agree with that one.

Hayley went on to explain that she wore the top for 'dressing up...just at home' because due to her mother's disapproval 'I'm not allowed to go out, am I?'. For both Hayley and Katy, their consumption of 'revealing' clothing was constrained by their mothers' ideas of what was acceptable for them to wear, and where. This provides a clear example of the kinds of power adults have over what children wear on their bodies, when and where, identified by Hood-Williams (1990), but also of the kinds of intergenerational negotiations that take place between parents and children (James, Jenks and Prout 1998; Prout 2000). The revealing tops at issue were purchased and worn, even though they were coded by the mothers as 'restricted', to be worn only in certain contexts. In Hayley's case, this meant only for 'dressing up' inside the house. For Katy's mother, Amanda, the school was an acceptable and known (safe) interior space/place and the disco an acceptable occasion for such restricted clothing to be worn, not least because 'other girls' there would also be wearing 
them. In alluding to the 'other girls', Amanda was also conceding the significance of peer relations for her daughter, of securing acceptance and a sense of belonging from wearing the 'right' clothes, that was also referred to by Katy in relation to her desire for high-heeled shoes. For Hayley, too, fitting in with peers was important in her liking for a crop top: 'I just kind of like it because everyone else has got one, so I kind of get one to fit in'.

We get a sense from Katy's discussion (above) that she likes tops which are not 'plain' and not 'normal'. Katy herself does not give the 'revealing' effect of their styling as her reason for liking to wear them. In her project work, Katy chose a picture of a 'one-shoulder' top ${ }^{4}$ as an item of clothes she would like because 'I like the style and I like the pattern'. In fact, none of the girls in our study spoke about the effect of revealing skin as an explicit reason for their liking, wanting or wearing such items of clothing. Emma (aged five) said she had an off-the-shoulder dress in pink, 'sort of see-through' material with 'a lot of sparkle'. For Emma, the attraction of the dress was more to do with the fabric and the embellishments than the bare skin the styling of the dress revealed. Susie (aged 10, and Katy's older sister) discussed her liking of halter-neck ${ }^{5}$ tops which she had 'a lot of' and also a mini-skirt, liked because of its elastic waist feature. Again, the bearing of skin through these favoured styles was not the issue but rather the hyper-feminine styling of the item in and of itself (see also Russell and Tyler 2002).

Hayley also had a gypsy-style top which she explained was 'like elasticated and you can pull it over [off] your shoulder'. For Hayley, though, this style of clothing was not suitable for wearing out to her church: the implication here is that this is because of the 'bare shoulder' effect of the top. Amongst the girls in our study, then, there is evidence of a desire for and active wearing of clothes that reveal skin. This effect was not, however, given as a reason for liking this clothing style, suggesting that such desires were 'innocent' of the 
symbolically sexual meanings of revealed feminine skin (Cook and Kaiser 2004; Kaiser 2001). Relatedly, in the girls' accounts of their preferences, neither was it suggested that the deliberate 'smallness' of the clothing style was used in order to 'age up' their bodies (Hockey and James 1993; Wright 1993).

\section{What not to wear: 'showing' your body}

Evidence presented so far shows, amongst the girls in our study, both a desire for and actual wearing of clothing styles that revealed bare flesh, including shoulders and upper chest areas, midriffs or bellies and the leg above the knee. Yet it is the styling of the clothes that was emphasized by the girls, not the revealing of the body they enabled. In contrast, when the girls spoke about their clothing dislikes, it was this very effect that they mostly objected to. In keeping with their earlier noted preferences, neither Katy (aged seven) or Megan (aged eight) expressed disapproval or rejection of revealing clothing styles. The other girls in our study reported their dislike and in some cases strong disapproval of 'showing' one's body via clothing.

For Emma (aged five) her dislike of tops with thin shoulder straps or those with off-theshoulder styling seemed more to do with the impracticality of the fit to her body. In her project, it was written that she disliked 'very thin straps on the shoulders which keep falling off her shoulders and down her arms'. For Hattie (aged 12, cousin to Emma and Jennifer), issues of impracticality combined with that of unwanted exposure of the skin in her account of 'revealing' clothing. Being a wheelchair user, and thus positioned lower down, gave Hattie and her mother special reason for caution in clothing styling in relation to exposure of the body. In her project, Hattie wrote 'I would also love to wear mini-skirts but as I am in a power chair all day these are not very practical as my legs would get very cold plus they are too short when sitting down'. As Hattie's mother explained, 'we have to be careful with the 
length of her skirts... we have to make sure it covers'. Hattie herself several times mentioned tops and a concern that her low sitting position made it easier for people (not specifically boys or men) to 'look down' at her chest. Baggy tops, for example, were said by Hattie to 'show too much cleavage' and made her worry that 'they are looking down my top', whilst 'revealing dresses' were disliked because they 'look too old on me and not very nice'. It is apparent here that Hattie is aware of the ways in which clothing can have the effect of 'ageing-up' the body to look older, an effect that she wants to avoid for herself. A mix of impracticality and the unwanted effect of the display of skin were also given by Jennifer (aged 9) in her account of styles she disliked. Jennifer disliked 'high heels' because they are 'too high up...I wouldn't walk very well in them. I'd fall over me'. Crop-tops were also included in her project as a disliked item of clothing because of the way they exposed skin: they 'show belly too much [sic]'. As in the case of Hattie, the identity of those to whom one's body is being 'shown' was not clear in the girls' accounts. There was an awareness that 'revealing' clothing makes the body and bare skin exposed to 'the gaze' - but it is the ungendered gaze of people in general, rather than particularly, say, boys or men.

For Hayley, it was not just the exposure of skin that was an unwanted effect of wearing 'revealing' clothing but also the risk of exposure of underwear. Hayley told us that 'I don't often wear my short red kilt because when I sit down it shows my knickers'. This particular girl also spoke about how her school uniform sometimes revealed her body in ways that she did not like: 'it gets a bit annoying sometimes because...if I wear a skirt and I choose to do cartwheels all day and that kind of gets a bit annoying because my skirt comes up'.

Hayley's comments here point to the way the more 'traditional' clothes girls are expected to wear (skirts and dresses) can act to inhibit girls in their physical performance of childhood, as discussed by Cahill (1989: 291). As for the other girls, though, for Hayley, it was 
revealing clothes (such as crop-tops) that 'show too much bare skin' that were especially problematical; her preference was for styles that she described as 'more covered'. In response to suggestions from the interviewer, Hayley said she would consider wearing a crop-top in contexts like on a beach or on holiday in a hot country. However, she would not walk through the High Street of her local town wearing it: 'God, no'. This example, along with the earlier described example of what not to wear to church, shows the understanding Hayley had of the symbolic value of clothing and its importance in the contextual presentation of self (Goffman 1969). This is an understanding also demonstrated by other girls in the study, including Megan and her 'going out night' clothes (see also below).

It is clear from the project work and interview data presented here that the girls' reasons for disliking 'revealing' clothing in relation to their own bodies centered on the unwanted effect of showing their skin or underwear. Although not clearly articulated by the girls, with the possible exception of Hayley, I suggest that their objections stemmed from a concern with modesty. In the girls' discussions of controversial clothing fashions worn by others, especially well-known celebrities including pop stars they had encountered through magazines or television, issues of modesty were addressed more clearly. Once again, the previously noted distinction drawn between 'dressing up' inside the house and 'dressing up' outside emerged in the girls' accounts.

Susie (aged 10) drew a picture of the singer Beyonce wearing high heels, short skirt and a string or halter-neck top. For Susie, like those in the pop group Liberty X, Beyonce is someone who 'sometimes the things she wears are a bit too skimpy...//. Short and a bit too...erm....(S. B.: You wouldn't go out in it?). Yeah (laughs)'. Elsewhere in her project, Susie included a picture of an off-the-shoulder crop top as an item she disliked because 'I can't really wear it out anywhere because it's a bit....(S.B.: Like something Beyonce would 
wear? ). Yes'. Like Beyonce, singer Kylie Minogue was another celebrity anti-role model for the girls in our study due to the styling of her clothing and the immodest bodily display it entailed. For Hattie (aged 12), Kylie Minogue 'wears too many short dresses and shows off too much of her legs'. The brevity or smallness of clothing was also a continuing theme in the project work completed by Hayley (aged 8). In a discussion of a crop-top style T-shirt, she came the nearest of all the girls to identifying the sexual meanings of such clothing styles. For Hayley, the T-shirt in question was 'Yuk...awful', due to a combination of its bright colour and it being 'too short': 'It's just a bit tarty and a bit showy'.

Our data suggest that the meanings the girls in the study gave to 'revealing' clothing were marked by some ambivalence. In relation to their own bodies, the girls stressed the styling and embellishments, the trendiness and fashion of clothing, over and above the effect of revealing their skin. When this effect was discussed, it was in most cases, unwanted and the cause of anxiety about being subjected to the gaze of unspecified others and in violation of a girl's sense of modesty in relation to her own body. In relation to the bodies of celebrity others encountered through popular media culture, an understanding of the symbolic value of clothing in terms of modesty and morality emerged strongly, over and above the styling, embellishment, 'trendiness' and fashion of the clothing itself. The small, short clothes (Wright 1993) may have been functional in that they were sufficient to actually cover the crucial areas of the women's bodies and prevent nakedness. Nonetheless, such clothes were coded by the girls as symbolically immodest, as 'not nice'. This points to the girls' knowledge and understanding of the symbolic value of clothing in relation to femininity, even if they did not fully articulate its gendered or sexualised component (see also Cook and Kaiser 2004; Russell and Tyler 2002).

\section{Conclusions}


The findings from our study point to the importance of not 'reading off' the meanings of girls' consumption of fashion styles from market trends, media debates, or the concerns of parents. For the girls in our study at least, controversial clothing held a range of contingent and often contradictory meanings. Some girls, like Hayley, wore contested items of footwear and clothing especially for playing 'dressing up' inside the house, in an articulation of children's distinctive 'tribal' culture (James, Jenks and Prout 1998). Others like Megan, wore them, as she put it, as 'going out night clothes' in a reflexive, knowing engagement with fashion trends. Such differences in the meanings girls' gave to their consumption of contested clothing, I argue, was at least partly contingent upon parental (especially mothers) views as to what their daughters were allowed to wear, and where, and to the subsequent negotiations between mothers and daughters. Importantly, though, the girls in our study also articulated their own reflexive and skilful understandings of how 'what to wear and where' is contingent upon contexts, both in relation to their own presentation of their embodied selves and when discussing the revealing clothing styles of women celebrities like Beyonce and Kylie Minogue. Although primarily suggestive, these aspects of our findings lend support to those authors like Sweetman (2001) who, in criticism of some postmodern consumption perspectives, insist that 'what to wear' (where and when) remains structured, at least in part, by statuses such as stage in life course and gender.

Controversial clothing was meaningful for girls in relation to their own desires to be 'fashionable', to dress their bodies in the ways that their peers (apparently) did. Here, emphasis was placed primarily upon the styling and embellishments of garments; in other words, it was the ways in which the garment was 'trendy' in and of itself. Arguably, then, those girls who desired and wore revealing clothing had been 'seduced' by the styling and embellishments of the garments over and above the accompanying and largely unwanted effect of revealing skin. One implication of this finding is that, to avoid the wrath of public 
debate and the antipathies of parents, clothing retailers should carefully attend to the use of the 'aesthetics of femininity' (Russell and Tyler 2002) in garments. These features make what might also be 'revealing' clothing items of desire for girls. Indeed, there is some evidence of sensitivity to this issue amongst major retailers in girls' wear. For example, Swedish-based H\&M have policy statements on children's clothing and publicly proclaim that 'we do not make clothes that may be perceived as provocative on small children' (H\&M 2002). Moreover, in our interviews with children's wear industry executives in England, several claimed to operate a policy of caution, albeit an unofficial one. As one executive for a major British retailer said, '[Our company] has a conscience...we won't do things that are too short', nor 'in a sexual way, because that's not what we are trying to convey'.

As I noted earlier, the effect of baring one's skin through revealing clothing was not explicitly valued by any of the girls. When discussing their feelings about wearing such clothes on their own bodies, and in discussion of the clothing styles of women celebrities, the girls expressed views to the effect that such clothing was immodest. 'Showing your body', for the girls in our study, was not a nice thing to do, whether it was Hayley playing handstands, Hattie in her wheelchair or Kylie Minogue on television. In this respect, then, concerns over damage to children's 'innocent' sense of morality through the sexualisation of girls' clothing, expressed within public debates about the erosion of childhood, are unfounded. Amongst the girls in our study at least, there was a strong sense of the morally symbolic meanings of clothing with respect to not showing the body. It is less clear, though, that the girls recognised the specifically sexual character of revealing clothing, or indeed had a firm sense of to whom the showing of the body was directed. The girls' consumption of revealing clothing, both in relation to their own bodies and in appraisal of celebrity others, can not be argued to be 'unknowingly innocent': they evaluated the clothing at issue in moral terms. Yet, neither were the sexual values of the clothing fully articulated by the girls. With 
this caveat about sexuality in mind, amongst the girls in our study, the evidence is rather mixed as to the extent to which there was a 'knowing' engagement with clothing fashions as the 'trappings' of femininity and of empowerment gained through such engagement (McRobbie and Nava 1984; McRobbie 1996; Russell and Tyler 2002). For girls in our study, like Hayley and Megan, it is evident that pleasure was gained through 'ageing up' (Hockey and James 1993), for example, through wearing high heels or dressing up in 'trendy' clothes, either as a form of play inside the house or for 'going out'. Moreover, both Megan and Hayley experienced a sense of empowerment through their precocious skill in being able to walk in high-heeled shoes. Yet, the wearing of such attire also acted to disempower the girls. Examples here include Hattie worrying about people looking up her skirt or down her top, and Hayley being concerned about showing her knickers when wearing short skirts or doing handstands. Through their appraisals of revealing clothing in terms of modesty, the girls in our study do demonstrate an ability to reflect critically on dominant images of the bodily styles of adult femininity. Yet, through their own practices of clothing consumption, it is clear that the girls also continued to include such styles of femininity in the selections they made from the range of clothing available to them, and in their constrained, but nonetheless, active and creative articulation of their own feminine childhoods.

\footnotetext{
${ }^{1}$ The wider sample of the study included two girls (sisters) of Pakistani heritage and whose religious affiliation was Muslim. In accordance with Muslim culture, Saima and Yasmeen expressed strongly disapproving views on 'revealing clothing' and material from their interviews and project work are not included in this paper.
} 
${ }^{2}$ All names used in the paper are pseudonyms.

3 'Gypsy' style tops are styled with heavily elasticated fabric across the chest, a feature that enables the wearer to pull the garment down off the shoulder to the upper arms, thereby fully exposing both shoulders, and the upper chest and upper back areas of the body.

${ }^{4}$ A top styled with only one shoulder covered with fabric or with a strap, leaving the other shoulder completely exposed.

${ }^{5}$ A top styled to fit the body via a neck fastening, and which exposes the shoulders, and upper back. 


\section{Bibliography}

Aldridge, A. (2004) 'Everyone's clamouring for slice of children's wear', Marketing, October 13.

Ash, J. and Wilson, E. (1993) 'Introduction', in Ash, J. and Wilson, E. (eds.) Chic Thrills. A Fashion Reader, Berkeley: University of California Press.

Cahill, S. (1989) 'Fashioning Males and Females. Appearance management and the social reproduction of gender', Symbolic Interaction 12 (2): 281-298.

Connell, R. (1995) Masculinities, Cambridge: Polity Press.

Cook, D. (2004) The Commodification of Childhood, Durham: Duke University Press.

Cook, D. and Kaiser, S. (2004) 'Betwixt and Be Tween. Age ambiguity and the sexualisation of the female consuming subject', Journal of Consumer Culture 4 (2): 203-227.

Craik, J. (1994) The Face of Fashion, London: Routledge.

Curtis, P. (2003) 'Teachers "must not become moral guardians"”, The Guardian, 30th July.

Edwards, T. (1997) Men in the Mirror: men's fashion, masculinity and consumer society, London: Cassell.

Elliot, R. and Leonard, C. (2004) 'Peer Pressure and Poverty: Exploring Fashion Brands and Consumption Symbolism among Children of the British Poor', Journal of Consumer Behaviour 3 (4): 347-359.

Entwhistle, J. and Wilson, E. (2001) 'Introduction: body dressing', in Entwhistle, J and Wilson, E. (eds.) Body Dressing, Oxford: Berg.

Euromonitor PLC (2004) 'Major Market Profiles - Clothing and Footwear', available at http://www.euromonitor.com/Clothingandfootwear

Goffman, E. (1969) The Presentation of Self in Everyday Life, London: Allen Lane 
H \& M (2002) Corporate Social Responsibility Report 2002, http://www.hm.com

Hammersley, M. and Atkinson, P. (1995) Ethnography, $2^{\text {nd }}$ edition, London: Routledge.

Hockey, J and James, A. (1993) Growing Up and Growing Old, London: Sage.

James, A. Jenks, C. and Prout, A. (1998) Theorising Childhood, Cambridge: Polity Press.

Jenks, C. (1996) Childhood, London: Routledge.

Johansson, B. (2004) 'Tweens in Consumer Society', Pluridisciplinary Perspectives on Child and Teen Consumption Conference, University of Poitiers, France, March, available at http://www.cemea.asso.fr/pdf/englishcolloque2526mars2004.pdf

Kaiser, S. (2001) 'Minding Appearances: style, truth and subjectivity', in Entwhistle, J and Wilson, E. (eds.) Body Dressing, Oxford: Berg.

Maffesoli, M. (1996) Time of Tribes, London: Sage.

Martens, L., Southerton, D. and Scott, S. (2004) 'Bringing Children (and Parents) into the Sociology of Consumption', Journal of Consumer Culture 4 (2): 155-182.

McRobbie, A. (1996) ‘More!: New Sexualities in Girls' and Women's Magazines’ in Curran, J., Morley, D. and Walkerdine, V. (eds.) Cultural Studies and Communications, London: Arnold.

McRobbie, A. and Nava, M. (1984, eds.) Gender and Generation, London: Macmillan.

Mintel (2003) Childrenswear Retailing, London: Mintel International Group. Pole, C., Mizen, P. and Bolton, A. (1999) ‘Realising Children’s Agency in Research: Partners and Participants?', International Journal of Social Research Methodology, Theory and Practice 2 (1): 33-54. 
Prout, A. (2000) 'Childhood Bodies: construction, agency and hybridity', in Prout, A. (ed.) The Body, Childhood and Society, London: Macmillan.

Russell, R. And Tyler, M. (2002) 'Thank Heaven for Little Girls: “Girl Heaven”, and the commercial context of feminine childhood', Sociology 36 (3): 619-637.

Swain, J. (2002) 'The "Right Stuff”: fashioning identity through clothing in a junior school', Gender and Education 14 (1): 53-69.

Sweetman, D. (2001) 'Shop-window dummies? Fashion, the body and emergent socialities', in Entwhistle, J and Wilson, E. (eds.) Body Dressing, Oxford: Berg.

Wright, L. (1993) 'Outgrown Clothes for Grown-up People', in Ash, J. and Wilson, E. (eds.) Chic Thrills. A Fashion Reader, Berkeley: University of California Press. 